\title{
Liter Per Hour Per Square Meter
}

National Cancer Institute

\section{Source}

National Cancer Institute. Liter Per Hour Per Square Meter. NCI Thesaurus. Code C105494.

A unit expressed as one liter of volume per unit of time equal to one hour per square meter of area. 